\title{
O ROMANCE AUTOBIOGRÁFICO DE ZELDA SAYRE FITZGERALD
}

\author{
Emanuelle Cristina de Oliveira Altieri ${ }^{1^{*}}$ \\ Cleide Antonia Rapucci ${ }^{1 * *}$ \\ ${ }^{1}$ Universidade Estadual Paulista, São Paulo, SP, Brasil
}

\begin{abstract}
Resumo
Este artigo $^{1}$ analisa o romance Save Me the Waltz (1932), de Zelda Sayre Fitzgerald, como sendo um romance autobiográfico, considerando as semelhanças entre os dados biográficos da autora e a construção da personagem principal, Alabama Beggs. A discussão aqui proposta busca analisar em que medida as trajetórias de Zelda e Alabama se cruzam considerando as opressões de gênero nas práticas sociais. As análises têm como base teórica autores como Philippe Lejeune (2014), Eurídice Figueiredo (2013) e Elaine Showalter (1986).

Palavras-chave: romance autobiográfico; Zelda Fitzgerald; crítica feminista
\end{abstract}

\section{ZELDA SAYRE FITZGERALD'S AUTOBIOGRAPHICAL NOVEL}

\begin{abstract}
This article aims to analyze Zelda Sayre Fitzgerald's novel Save Me the Waltz (1932) as an autobiographical novel, considering the similarities between the author's biographical data and de main character's construction, Alabama Beggs. The discussion presented proposes to analyze to what extend the paths of both Zelda and Alabama intertwine considering gender oppression in social practices. The analyses have as theoretical basis authors such as Philippe Lejeune (2014), Eurídice Figueiredo (2013) and Elaine Showalter (1986).

Keywords: autobiographical novel; Zelda Fitzgerald; feminist criticism
\end{abstract}

\footnotetext{
" Concluiu o mestrado (2020) na área de Literatura e Vida Social na Faculdade de Ciências e Letras de Assis - UNESP, com bolsa CAPES, e orientação pela Dra. Cleide Antonia Rapucci. A pesquisa contemplando a crítica feminista, literatura de língua inglesa, escritas de si e análise literária resultou na dissertação intitulada Emancipação e silenciamento em Save Me the Waltz (1932), de Zelda Fitzgerald. Tem graduação no curso de licenciatura Letras Português/Inglês também pela FCL - UNESP Assis. E-mail: manu_altieri@hotmail.com ORCID: https://orcid.org/0000-0002-0335-8193.

" Cleide Antonia Rapucci é Doutora em Letras pela Universidade Estadual Paulista/Assis, instituição na qual é professora do Departamento de Letras Modernas e leciona desde 1990. Na Graduação em Letras, é responsável pelo conjunto de disciplinas de Literaturas de Língua Inglesa. Já no Programa de Pós-graduação em Letras, orienta Mestrado e Doutorado na área de literatura de autoria feminina e crítica feminista. Atualmente, desenvolve projeto acerca das configurações do espaço nos romances de Angela Carter. Email: cleide.rapucci@ unesp.br. Orcid: https://orcid.org/0000-0002-1388-8470.
} 


\section{Introdução}

Em meio a grande prosperidade da chamada Era Progressista dos Estados Unidos da América, a década de 1920 fincou-se na história como um período de avanços tecnológicos, urbanização, modernidade e efervescência cultural. A sociedade norte-americana desvelava-se das tensões causadas pela Primeira Guerra Mundial, na qual participaram de 1914 a 1918, ao mesmo tempo em que os jovens embalavam-se nos ritmos jazzísticos e enunciavam um estilo de vida mais hedonista e rebelde.

As mudanças que aconteceram devido à guerra, desde o aumento de mulheres no mercado de trabalho, até a urbanização do país no período entreguerras, acarretaram importantes transformações sociais. A Associação Nacional Americana para o Voto das Mulheres (National American Woman's Suffrage Association), devido a um sólido movimento que reivindicava o voto feminino, a igualdade legislativa e a reforma das leis do divórcio, por exemplo, conquistou o direito de voto às estadunidenses em 1920 (ZOLIN, 2005, p. 184). Durante esse período, um número maior de mulheres de classe média ocupou diferentes postos de trabalho, atuando como jornalistas, professoras, ativistas ou empresárias, mesmo após se casarem (SCOTT, 1995, p. 227).

Nesse momento de cisão, a flapper aparece em embate com o discurso da geração anterior, que desprezava álcool e cigarros, enquanto valorizava uma "voz suave" (SCOTT, 1995, p. 226), ou seja, a sociedade em si vivenciava o embate do que era "velho" com o "novo" e "moderno", e as questões de gênero não escapavam a isso. Evidenciando uma nova forma de se vestir e de se comportar: vestimentas mais reveladoras, mais maquiagem (especialmente batom), cigarros e joias maiores, além das danças com outras pessoas, a flapper era a mulher moderna e mostrava algumas mudanças de atitude em relação a suas mães e avós (STREISSGUTH, 2007, p. 43).

Conforme constata Anne Firor Scott, em seu livro The Southern Lady, "Não tem como comparar a angústia de ter que escolher com a angústia de não ter escolha" (1995, p. 220, tradução nossa) ${ }^{2}$. Assim, considerando as novas transformações em curso no período, um novo leque de possibilidades se apresentava diante da geração de mulheres na década de 1920 até mesmo em regiões tradicionalmente mais conservadores dos Estados Unidos da América (ainda que a passos mais lentos).

De Southern Belle à flapper, Zelda Sayre Fitzgerald consagrou-se como uma icônica figura dos chamados The Roaring Twenties, também conhecidos como os loucos anos vinte. Zelda nasceu no dia 24 de julho de 1900 em Montgomery, Alabama. Ela era filha de Minnie Machen e de Anthony Dickinson Sayre. Cresceu em contato com vários tipos de arte, tendo suas próprias aspirações artísticas desde jovem. Em carta enviada a F. Scott Fitzgerald no outono de 1919, percebese seu interesse pela escrita: 
Ontem quase escrevi um livro ou conto, ainda não me decidi qual [...] "Vamping Romeo" era o nome e desconfio que a certa altura, antes do fim, algum homem teria que ter aparecido. (BRYER; BARKS, 2005, p. 77).

Também se interessava por desenho, pintura e dança, tendo criado produções nesses diferentes campos artísticos. Ela escreveu contos, artigos para revistas, peça de teatro e o romance intitulado Save Me the Waltz, publicado pela primeira vez em 1932, e é possível ver os escritos reunidos e publicados em 1991 no compilado Zelda Fitzgerald: The collected writings (2013). A primeira edição do romance em português foi publicada pela Companhia das Letras em 1986, com tradução de Rosaura Eichenberg, e relançada em 2014, trazendo o título Esta Valsa é Minha. Zelda também teve suas cartas de amor reunidas na obra Querido Scott, querida Zelda (2005), publicada em português pela Companhia das Letras.

Embora tenha explorado diferentes territórios artísticos, foi por muito tempo vista à sombra de seu marido, o escritor norte-americano F. Scott Fitzgerald, ou estigmatizada por sua condição psicológica. Tal constatação é amparada, por exemplo, pelo prefácio escrito na primeira edição de Save Me the Waltz, por Harry T. Moore, ao afirmar que "trata-se de uma curiosidade literária [...] Esta valsa é minha pode não ter a arte perfeita da obra de Scott Fitzgerald" (MOORE, 2014, p. 295-300) na leitura que precede o romance.

No artigo "Uma Vasta Surpresa: os prefácios ao romance de Zelda Sayre Fitzgerald”, de Marcela Lanius e Marcia A. P. Martins (2019), em análise do prefácio mencionado, constatam que:

É provido desses argumentos que o crítico dedicará os últimos cinco parágrafos de seu prefácio não à uma análise de Save me the Waltz, mas sim ao enaltecimento de Tender is the Night. Louca, invejosa, silenciada e, portanto, menor - é a Zelda Sayre Fitzgerald imortalizada no prefácio de sua própria obra; prefácio este que acompanhava, até 2001, as reedições em língua inglesa do livro (LANIUS; MARTINS, 2019, p. 213).

Outras críticas e outros estudos apareceram reconhecendo a importância de Zelda Fitzgerald como importante voz de sua geração, a começar pela biografia Zelda, de Nancy Milford (1970). Há artigos e capítulos de livros como de Tavernier-Courbin em “Art as Woman's Response and Search: Zelda Fitzgerald’s Save Me the Waltz" (1979), "Save Me the Waltz an assessment in craft" (1982), de Linda Wagner, de Sarah B. Fryer em "Nicole Warren Diver and Alabama Beggs Knight: Women on the threshold of freedom" (1985) e "The Cult of Artistry in Zelda Fitzgerald's Save me the Waltz" (2014) de Rickie-Ann Legleitner, entre outros. E discutindo a obra dentro de diferentes gêneros, mas em especial o romance sulista, há o capítulo "Zelda Fitzgerald's Save Me the Waltz as Southern Novel and Künstlerroman" de Lisa Nanney, do livro The Female Tradition in Southern Literature (1993).

Por ter sido uma icônica figura no tempo em que viveu, os conhecidos dados biográficos fazem com que seu romance seja lido como "autobiográfico", uma vez que é possível encontrar uma série de paralelos e semelhanças. Ao afirmar que 
Save Me the Waltz é uma autobiografia ou um romance autobiográfico, faz-se necessário revisar que tipo de pacto de leitura se faz com o leitor, e qual a proposta da autora, uma vez que há particularidades do gênero autobiografia e do gênero romance autobiográfico que os diferem. A autobiografia passou a ser objeto de estudo literário de forma sistemática a partir da década de 1970 com as publicações de Philippe Lejeune na França, que propôs discussões e ideias como o "pacto autobiográfico", essenciais para o entendimento do gênero.

O presente artigo se debruça sobre Save Me the Waltz no tocante às "escritas de si”, trazendo à luz a autora Zelda Sayre Fitzgerald e a personagem Alabama Beggs, a fim de buscar uma categoria mais alinhada com essas perspectivas que cambaleiam entre a "vida real" e a ficção; ora artista e personagem se encontram, ora seguem caminhos diferentes. Para pensar os gêneros das "escritas de si", a discussão proposta parte de Lejeune, com O pacto autobiográfico (2014) e contempla também as reflexões de Eurídice Figueiredo em Mulheres ao espelho (2013).

A crítica feminista aparece como uma ferramenta precisa dentro da análise, uma vez que Alabama Beggs, a personagem principal, é construída dentro da narrativa traçando uma jornada interna que parte de uma família de forte tradição patriarcal, para a tentativa, parcialmente frustrada, de romper com essa tradição dentro de seu casamento. O termo patriarcal, segundo Zolin, designa "uma espécie de organização familiar originária dos povos antigos, na qual toda instituição social concentrava-se na figura de um chefe, o patriarca, cuja autoridade era preponderante e incontestável" (ZOLIN, 2005, p. 183). Destarte, os estudos de Elaine Showalter (1986) sobre a literatura de autoria feminina serão norteadores ao se pensar tanto a autoria feminina em si quanto o desenvolvimento $\mathrm{da}(\mathrm{s})$ personagem(ns).

\section{A imagem refletida: uma verdade interior}

Marcado pela temática da jornada interna, Save Me the Waltz parte da infância de Alabama Beggs até a idade adulta; da vida com os pais e as irmãs até casar-se e ter uma filha; das flores e insetos que invadiam a varanda dos Beggs no sul dos Estados Unidos, até Connecticut, Riviera Francesa, Paris, Nápoles e de volta ao sul - completando uma jornada que se faz cíclica como o compasso ternário de uma valsa.

Considerando a análise da narrativa do romance, a história de Alabama é contada pelo narrador em terceira pessoa - o narrador que é heterodiegético (GENETTE, 1995, p. 244). Assim, o narrador está ausente da história que conta, de longe do percurso de Alabama Beggs, o qual parte de sua infância e segue até a vida adulta, cronologicamente, embora o tempo não seja explicitamente marcado. No entanto, é possível notar algumas marcas temporais sutis ao longo da narrativa, que indicam o ano ou algum momento histórico.

A história de Alabama perpassa primeiro pelos dias sob a tutela de uma figura materna generosa, que conquistara "uma harmonia de santa" (FITZGERALD, 2014, p. 11), e uma figura paterna austera, com regras rígidas e um acentuado 
senso de ordem. Millie, a mãe, é apresentada com uma série de características consideradas "femininas", como a doçura, a modéstia, a subserviência, a humildade (MOI, 1989, p. 122-123), elencadas como o "padrão de feminilidade". Notase como sua "generosidade sem lei" se faz em contraposição à "lógica irrefutável" (FITZGERALD, 2014, p. 20) do homem que é um juiz, profissão intimamente ligada à lei, colocando o homem com características opostas às da mulher:

A ampla generosidade sem lei da mãe fora alimentada por muitos anos de convivência com a lógica irrefutável da fina mente do juiz. Como uma existência em que a tolerância feminina não tivesse vez fosse insuportável a seu temperamento maternal, Millie Beggs se tornara, aos quarenta e cinco anos, uma anarquista emocional. (FITZGERALD, 2014, p. 20, tradução nossa). ${ }^{3}$

Mostrando, ao longo da infância e da juventude, um espírito curioso e subversivo, Alabama buscava preencher-se com "uma interpretação de si mesma" (FITZGERALD, 2014, p. 12), ou seja, autoconhecimento, sendo um ponto recorrente no Capítulo 1. Dentre esses momentos de descoberta, o espelho aparece de forma realçada, principalmente quando o pai indica que ela sempre está se observando: "Ela sabia, porém, que se olhava com mais frequência do que a satisfação com a aparência justificava, na esperança de encontrar algo maior do que esperava." (FITZGERALD, 2014, p. 41). ${ }^{4}$

Segundo o Dicionário de Símbolos de Chevalier e Gheerbrant (CHEVALIER; GHEERBRANT, 2009, p. 393-396), o espelho reflete a verdade, a sinceridade, o conteúdo do coração e da consciência. Portanto, quando a pessoa olha para um espelho, o objeto pode também refletir a verdade interior do ser humano. No caso de Alabama, essa interpretação sobre o espelho se sustenta pela grande busca da personagem por se conhecer, como um instrumento para seguir rumo ao seu futuro. Não só o espelho, mas a própria família também era vista como possível fonte desse entendimento:

Escutar pedaços de comentários sobre características da família que ela também deveria possuir era como descobrir que tinha todos os cinco dedos no pé, quando até o presente só conseguira contar quatro. Convinha ter indicações sobre si própria para ir adiante. (FITZGERALD, 2014, p. 31). ${ }^{5}$

Alabama, em meio a agitada juventude, mas ainda sob o zelo da figura paternal, conhece e se apaixona por um tenente aspirante a pintor. É com ele que ela se casa e tem uma filha, Bonnie. Quando se conheceram "David, David, Knight, Knight, Knight e srta. Alabama Ninguém" (FITZGERALD, 2014, p. 53) ${ }^{6}$ foi como David registrou o primeiro encontro na ombreira de uma porta do clube.

Quem também aborda o espelho como metáfora para as opressões de gênero é Virginia Woolf em Um teto todo seu. A autora de Mrs. Dalloway afirma que: "As mulheres têm servido há séculos como espelhos, com poderes mágicos e deliciosos de refletir a figura do homem com o dobro do tamanho natural." (WOOLF, 2014, p. 54). Ao contrário de Alabama, David se via com completude 
diante do espelho. "Ele se olhou no espelho [...] como se fizesse um inventário de si mesmo antes de sair e ficasse satisfeito por se ver completo." (FITZGERALD, 2014, p. 55). ${ }^{7}$

David e Alabama existem e coexistem em dualidade - enquanto Alabama se vê guiada por uma busca interna, sugerindo incompletude, ele se vê "com completude", além de afirmar e reafirmar o próprio nome e sobrenome sobre os dela. O status quo do sobrenome Beggs se transforma em "Nobody" (em português, "Ninguém") na ombreira da porta anulando o peso do sobrenome que a garota herdara de seu pai, um estimado juiz, e que porquanto sugeria prestígio social naquela cidade.

Ao se casarem, Alabama tornou-se, nas palavras encontradas no próprio livro, "os David Knight". Com o passar do tempo e em meio a momentos conturbados no relacionamento, David se tornou um reconhecido pintor e criticava Alabama sobre os afazeres cotidianos e domésticos. Questões ligadas à traição apareceram de forma sugestiva, relacionadas a ambas as partes. O momento em que Alabama decidiu começar a dançar foi marcado pela insegurança ao saber que David estava na companhia de outra mulher, enquanto ela assistia a um balé, arte que praticara quando criança, e pode-se ver logo nas primeiras páginas do romance:

\begin{abstract}
"Não me importo", ela repetiu convicta para si mesma: uma incisão tão exata no tecido da vida como só o cirurgião mais hábil poderia ter esperanças de produzir sobre um apêndice inflamado. Registrando as suas impressões como uma pessoa fazendo um testamento, ela legou cada sensação passageira à momentânea acumulação de seu ser, o presente, que se enchia e esvaziava com os transbordamentos. (FITZGERALD, 2014, p. 161). ${ }^{8}$
\end{abstract}

A tentativa de indiferença demonstra o que pode se associar à "harmonia de santa" de Millie Beggs, marcada como característica do esperado papel "feminino". Millie cuidava para que houvesse harmonia no lar, assim o marido poderia estudar ou trabalhar. Desse modo, a ordem da casa e da estrutura patriarcal mantinham-se operantes, bem como o casamento. Alabama, por sua vez, pela "incisão no tecido da vida" foi motivada a buscar uma mudança significativa, e o termo "incisão" antecipa o trágico fim da personagem, que é impedida de dançar por conta de uma "incisão" nos tendões. Mas a trajetória artística implica grandes conflitos no casamento, já que a dedicação exaustiva à dança incitou a resistência de David, que em certos momentos recriminou a dedicação ou inferiorizou-a falando que era amadora.

Enquanto treinava as técnicas de dança e ensaiava, Alabama se via no estúdio em um grande espelho e reconquistava ali o direito de ser "Alabama", não permitindo que David Knight ou os amigos de seu companheiro invadissem o lugar que se tornara seu domínio. Alabama, por meio de seu próprio corpo em movimento, ressignificou as expectativas de sua individualidade perante o mundo, o que fez com que ela se colocasse como sujeito e agente da ação artística.

O estúdio de dança se tornou o ateliê de Alabama. Seguindo a esteira da crítica feminista, o corpo, para a mulher, é, segundo o Dicionário de Crítica Feminista, 
uma entidade politicamente inscrita, "sendo a sua fisiologia e morfologia moldada e marcada por práticas históricas de condicionamento" (MACEDO; AMARAL, 2005, p. 25), e é pelo movimento do corpo que Alabama busca sua sublimação.

Parecia a Alabama que, ao atingir seu objetivo, ela afastaria os demônios que a tinham dominado - que, ao se pôr à prova, conseguiria aquela paz que imaginava só existir com a autoconfiança -, que seria capaz, por intermédio da dança, de controlar suas emoções, de chamar o amor, a piedade, ou a felicidade quando quisesse, tendo providenciado um canal por onde pudessem fluir. (FITZGERALD, 2014, p. 171). ${ }^{9}$

$\mathrm{Na}$ trajetória como mulher-artista, dedicando-se à dança, Alabama aceitou um convite para dançar em Nápoles. O convite marcava, portanto, o momento de maior autonomia e independência financeira da personagem. Seguiu viagem sozinha de trem nas condições que poderia pagar sozinha, enquanto David seguiu com Bonnie, a filha do casal, para a Suíça. Lá ela conseguiu ganhar algum dinheiro e prosseguir na carreira que sonhara, mantendo contato com a família à distância. Todavia, Alabama precisou ser internada por conta de uma infecção no pé, causada pela cola da sapatilha de ponta, tendo sua trajetória artística interrompida pela internação que levou à incisão nos tendões.

Dada a importância do corpo e do espelho dentro de Save Me the Waltz, é imperativo abordar as características da personagem. As descrições físicas tecidas na narrativa sobre a personagem principal indicam uma jovem do sul dos Estados Unidos cujos cabelos são dourados e o rosto brilhava quando perto do fogo. Cores quentes como o amarelo e o dourado, utilizadas para descrever a personagem, são também as cores utilizadas para descrever o sol e o calor, muito próprios dos cenários do sul. Alabama aparece constantemente tomando sol, e vê-se no trecho a seguir um momento em que é recriminada pelo pai:

[...] o Sul se expressava com um convite colorido - para uma festa sem endereço. - Millie, você não deveria deixar que Alabama fique tão queimada de sol, se ela vai usar esse tipo de roupa. (FITZGERALD, 2014, p. 41). ${ }^{10}$

A cor amarela também está presente no hospital, quando Alabama está internada e seus pés encontram-se presos por roldanas pesadas que a deixam com o corpo todo dolorido. Operando agora como fator farmacológico, o amarelo é a cor do calmante que Alabama toma quando está em Nápoles e, por fim, também se apresenta quando Millie conta que as flores amarelas eram as favoritas do juiz Beggs.

Sendo "Knight" em inglês uma palavra homófona a "night", que significa noite, nota-se uma ligação com a lua: "[...] enquanto você é um sujeito lunar" (FITZGERALD, 2014, p. 118) ${ }^{11}$ conforme assinalou Alabama na Riviera Francesa. David aparece não só ligado à noite e à lua, mas também ligado ao azul reforçando os contrastes presentes entre as personagens. O céu lunar de David coloca-se então em contraste com o amarelo sol de Alabama. 
Eurídice Figueiredo (2013, p. 24) afirma que o correspondente da autobiografia na pintura é o autorretrato, praticado por grandes artistas. Assim como se colocam na tela enquanto pintam, como Velasquez no quadro As meninas, Zelda pintou em Alabama um autorretrato, cujas linhas distorcidamente arredondadas e as cores amareladas deram forma ao rosto reconhecível em fotografias e registros documentais da autora. É possível encontrar o autorretrato de Zelda na seção de portfólio em The Romantic Egoists (BRUCCOLI; SMITH, 2003, p. 191) junto a algumas outras pinturas.

Lejeune, em 1986, ao estender seu olhar sobre autorretratos, afirmou que "o autorretrato é, na verdade, no sentido religioso, uma aparição. O espírito criador se encarna em uma das figuras de sua criação, se projeta e se encara" (LEJEUNE, 2014, p. 288). O autor também faz uma associação entre a tela e o espelho:

Se eu imaginar que a tela é espelho, ela desaparece como pintura. O autorretratista via em seu espelho um quadro (por fazer); eu vejo em seu quadro (feito) um espelho. O quadro é como um espelho sem aço: o pintor está atrás (do outro lado em relação a mim), e eu o surpreendo se olhando. Com isso, nos tornamos... contemporâneos. (LEJEUNE, 2014, p. 285).

Ao constatar que "A autobiografia é nítida em Esta valsa é minha. De certa forma parece a versão pessoal de Zelda a tudo que Scott contaria em Suave é a noite [...] Aqui, ela chama-se Alabama [...]" (ABREU, 2014, p. 292), assume-se a leitura da obra como uma leitura em alguma medida autobiográfica. O rosto de Zelda Sayre Fitzgerald desvela-se, então, não só nas pinceladas distorcidas do autorretrato que certa vez pintara, mas também no espelho "distorcido" que mostra a face de Alabama Beggs, com as linhas que se somam em um romance.

\section{A impossibilidade frente à opressão}

Showalter (1986, p. 12) dividiu as fases de literatura de autoria feminina em três, de acordo com o que seria um tipo de padrão para grupos socialmente oprimidos: a primeira (fase feminine) consiste na imitação da tradição dominante, a segunda (fase feminist) consiste em protesto aos valores dominantes e, a terceira (fase female), na autodescoberta e busca de identidade própria. Essa divisão vem da relação estabelecida entre as mulheres escritoras e a sociedade em que estão inseridas, considerando uma rede de influências que opera sobre o texto, arranjado em palavras e em linguagem (SHOWALTER, 1986, p. 12). Dessa maneira, as experiências e vivências comuns entre as mulheres explicariam as diferentes fases presentes nos textos de autoria feminina. Segundo Bellin (2011), ao considerar os aspectos extratextuais na análise de uma obra:

[...] uma leitura feminista e/ou de gênero, leva em consideração, na análise de uma obra, o gênero do autor, o gênero do leitor e as configurações sociais que permeiam a vida de homens e mulheres, o que não quer dizer que o texto literário seja uma "cópia" ou um mero reflexo da realidade, 
pelo contrário: ele é um amálgama de dados ficcionais e reais, de forma que a realidade nunca é refletida na estrutura ficcional, e sim filtrada por fatores estéticos. (BELLIN, 2011, p. 10).

Pelas definições de Showalter, a obra Save Me the Waltz pode ser entendida como pertencente à fase feminista, uma vez que o papel secundário da mulher dentro de um determinado contexto histórico e social faz-se fundamental para se entender a história de Alabama em um período em que os valores patriarcais eram dominantes, ainda que houvesse grandes transformações a favor das mulheres, como o direito ao voto. Alabama percebe as opressões nas práticas sociais e expressa essa consciência em alguns momentos, como ao falar para sua filha "-É um mundo de homens - suspirou Alabama, medindo-se num raio de sol. - Este ar tem um efeito lascivo..." (FITZGERALD, 2014, p. 112). ${ }^{12}$

Alabama e Millie representam duas gerações diferentes de mulheres em relação aos seus núcleos familiares centrados na figura do homem que trabalha, provém e, portanto, atua na esfera pública da sociedade. Quando Alabama conseguiu concretizar seu sonho de ser bailarina, longe da família, o acidente em seu pé a faz ser obrigada a voltar para a esfera doméstica. Seu marido, por outro lado, continuou exercendo seu ofício de pintor e o fez perversamente - pintando bailarinas.

David eterniza a arte do balé e também a silencia nas telas dos quadros; ele fagocita o desejo de Alabama e o coloca como inspiração, objeto da atividade artística do homem (como a musa). A dualidade e contraposição entre a dança de Alabama e o quadro de David se fazem com, respectivamente, movimento e inércia, som e silêncio. É como se "David, David, Knight, Knight, Knight e srta. Alabama Ninguém” (FITZGERALD, 2014, p. 53) se concretizasse nesse fim, por afirmar a possibilidade dele sobre a impossibilidade dela em relação a um mesmo objeto artístico.

Zelda, por ser recorrentemente vista em função de F. Scott Fitzgerald ou como musa de suas obras, teve também problemas em relação a sua arte. A própria autoria de algumas publicações foi comprometida, como pode-se notar em:

Em 1929-1930 Zelda escreveu 5 "sketches" para College Humor. A revista insistiu que o nome de Scott fosse incluído na autoria. A sexta história, " $A$ Millionaire's Girl", apareceu na The Saturday Evening Post creditada apenas a F. Scott Fitzgerald, por causa de um erro no escritório Ober. (BRUCCOLI; SMITH, 2003, p. 170, tradução nossa). ${ }^{13}$

Pode-se perceber que Alabama se depara com uma espécie de beco-sem-saída do feminismo, próprio da fase feminista apontada por Showalter uma vez que a tomada de consciência da personagem se frustra na impossibilidade de romper com a ordem dominante. Zelda, por sua vez, também se deparou com a impossibilidade frente a sua atividade artística - por vezes, impossibilidade até mesmo de deter a autoria exclusiva dos contos que escrevera, sendo obrigada a "compartilhar" com o marido. Em The Romantic Egoists (BRUCCOLI; SMITH, 2003, p. 170-171) é possível ver uma série de contos com autoria atribuída a "F. Scott and Zelda Fitzgerald", por exemplo "Southern Girl” ou "The Girl the Prince Liked". Tal 
qual Alabama, a tentativa de atividade artística é rompida ou minada, colocando a mulher como secundária de sua própria atividade ou da própria vida.

Em meio a delicadas questões enfrentadas por Zelda Sayre Fitzgerald, suas cartas nos períodos de internação são sensíveis registros da vivência que ruminam tópicos profundamente existenciais:

Meu querido - desconfio que vou passar o resto da vida despedaçada entre o desejo de dominar a vida e a sensação de que ela é, au fond, um inimigo desdenhoso [...] não há nada mais sórdido do que viver trancafiada - Quando o homem não é mais seu próprio dono, guardião de suas próprias tolas vaidades e satisfações infantis, não é nada de nada - sendo antes de tudo só um agente de um estágio muito experimental de livre-arbítrio orgânico (BRYER; BARKS, 2005, p. 204).

O fragmento acima foi escrito em março de 1932. Tanto o itinerário de Zelda quanto o de Alabama perpassam por angústias físicas ou emocionais, e ao menos parte delas é articulada nas palavras que Zelda deixara; seja em suas cartas, onde pode-se ver tocantes indagações que remetem a questionamentos humanos e filosóficos; seja em sua arte, onde sua habilidade se apresenta com pitadas maiores ou menores de imaginação.

\section{A autobiografia e o romance autobiográfico: a princesa na torre de marfim}

Roland Barthes em A morte do autor afirma que "a escritura é a destruição de toda a voz, de toda a origem" (BARTHES, 2012, p. 57). Para Barthes, a multiplicidade de escrituras, oriundas de diferentes culturas, não se encontra no autor, mas no leitor, que seria "um homem sem história, sem biografia, sem psicologia" (BARTHES, 2012, p. 64). Dito isso, é preciso "inverter o mito: o nascimento do leitor deve pagar-se com a morte do Autor" (BARTHES, 2012, p. 64) prevendo, portanto, a atitude de esvaziar o autor como detentor da origem e do sentido do texto. Figueiredo (2003), entretanto, aponta para a completude da volta do sujeito com Roland Barthes por Roland Barthes (1975), oito anos após a publicação de A morte do autor:

um livro de fragmentos, em forma de aforismos, máximas, no qual predomina o uso da terceira pessoa. Não é propriamente uma autobiografia; contém alguns biografemas, faz referência à homossexualidade, às suas enxaquecas, a algumas poucas recordações da infância (anamneses). Há nele um hibridismo genérico que mistura ensaio, fotografia e recordações pessoais. Não é confessional, trata de alguns assuntos como amor e sexo de maneira distanciada; em alguns poucos momentos pode-se sentir os afetos que o movem, seu sentimento de ser marginal quando diz que o natural na França é ser católico, casado e ter um bom diploma, ou seja, tudo que ele não era. (FIGUEIREDO, 2013, p. 20-21).

Ainda segundo Figueiredo (2013, p. 21) nota-se um certo pudor do autor ao falar de si mesmo: 
a primeira frase do livro (no verso da capa da edição francesa) é: "Tudo isto deve ser considerado como dito por um personagem de romance", ou seja, ele toma distância de si, ou melhor, pede que o leitor tenha um recuo em relação à identidade autor-narrador-personagem. (FIGUEIREDO, 2013, p. 22).

A complexidade do gênero autobiográfico remonta o desafio de pensar os aspectos extratextuais de uma obra - na contramão de Barthes em A morte do autor e da perspectiva estruturalista - organizando-se algumas normas para reconhecê-lo e pensar as obras dentro dele. Um dos principais teóricos sobre o gênero é Philippe Lejeune, que publicou seu primeiro livro sobre o assunto, L'autobiographie en France (1971), buscando um modo de legitimar o gênero. Em sua obra O pacto autobiográfico (2014), o autor propõe alguns caminhos possíveis para refletir sobre o que seria uma obra autobiográfica nos capítulos "O pacto autobiográfico" (publicado na revista Poétique e, em 1975, pela Seuil), "O pacto autobiográfico (bis)" (1986) e "O pacto autobiográfico, 25 anos depois” (2001). A edição contempla três décadas da aventura teórica do autor em seus ensaios a respeito da autobiografia (e outros mais), contando com uma revisão das próprias ideias.

A começar pela definição de autobiografia proposta por Lejeune em um primeiro momento (LEJEUNE, 2014, p. 16), o autor afirma: "trata-se de uma "narrativa retrospectiva que uma pessoa real faz de sua própria existência, quando focaliza sua história individual, em particular a história de sua personalidade". Nesse sentido, para existir a autobiografia, Lejeune coloca a necessidade do nome próprio para garantir a identidade de nome entre o autor, o narrador e a pessoa de quem se fala (LEJEUNE, 2014, p. 28). Além disso, para que o gênero se estabeleça como tal, é necessário o "pacto autobiográfico" (LEJEUNE, 2014, p. 30), o qual requer que uma afirmação seja feita ao contar a história da própria vida, e um compromisso estabelecido entre a unidade autor-narrador-personagem, no qual o autor asseguraria contar a verdade, que guiaria a leitura.

Como uma ramificação do gênero, nesse primeiro momento, Lejeune traz também o "romance autobiográfico":

Chamo assim todos os textos de ficção em que o leitor pode ter razões para suspeitar, a partir das semelhanças que acredita ver, que haja identidade entre autor e personagem, mas que o autor escolheu negar essa identidade ou, pelo menos, não afirmá-la. Assim definido, o romance autobiográfico engloba tanto narrativas em primeira pessoa (identidade do narrador e do personagem) quanto narrativas "impessoais" (personagens designados em terceira pessoa); ele se define por seu conteúdo. (LEJEUNE, 2014, p. 29).

Quanto à identidade afirmada no texto, a diferença seria em relação à gradação: o romance autobiográfico comportaria graus, enquanto que na autobiografia "é tudo ou nada" (LEJEUNE, 2014, p. 25), esse apontamento sobre a identidade e a autobiografia é, depois, flexibilizado pelo teórico. Figueiredo, sobre o romance autobiográfico, afirma: 
No romance autobiográfico canônico não existe identidade nominal entre personagem, narrador e autor, ou seja, o personagem tem um nome fictício, mas muitas vezes os leitores se dão conta de que o romance tem um fundo autobiográfico; isso se acentuou nos últimos anos, com o maior acesso à informação. (FIGUEIREDO, 2013, p. 41-42).

Ou seja, conhecendo dados e informações sobre uma personalidade, mesmo que a identidade nominal não apareça, o "fundo autobiográfico" que se apresenta como matéria-prima norteia o leitor, possibilitando que o conteúdo da obra dialogue com o conteúdo conhecido da vida de quem escreve.

Trinta anos após a primeira publicação de "O pacto autobiográfico", Lejeune (2014, p. 87) reafirmou a necessidade de o autor declarar sua intenção, como uma promessa ou proposta, para que haja autobiografia. Não caberia ao leitor fazer suposições - mesmo que, para acontecer o pacto, o leitor também deva comprometer-se com a proposta, uma vez que é livre para ler como quiser. Todavia, firmando ou não o pacto, o leitor o considera, pois ele existe.

O pacto autobiográfico pode ocorrer de forma menos explícita em comparação com a primeira defesa de Lejeune. Em “O pacto autobiográfico (bis)", Lejeune (2014, p. 68) considera, por exemplo, casos em que o nome do personagem não é idêntico, mas semelhante ao nome do autor, como pode-se observar:

Hoje, sei que transformar sua vida em narrativa é simplesmente viver. Somos homens-narrativa. A ficção significa inventar algo diferente dessa vida [...]. Não, a autobiografia não é um caso particular de romance, nem o inverso, ambos são casos particulares de construção de narrativa. (LEJEUNE, 2014, p. 86).

Zelda Sayre Fitzgerald, escreveu Save Me the Waltz na clínica psiquiátrica Henry Phipps e o dedicou à sua médica, Dra. Mildred Squires. Com a escrita ornamental e descritiva e com a temática da busca por autoconhecimento recorrente no romance, em Querido Scott, querida Zelda o estilo de escrita e a "busca por si” também são perceptíveis, como afirmam Jackson R. Bryer e Cathy W. Barks:

[...] existe uma coerência surpreendente nas cartas, que transparece em dois temas recorrentes e dignos de nota: primeiro, como seu relacionamento com Scott era fundamental; segundo, como sentia vontade, estralhaçada como estava, aos trinta anos de idade, de encontrar algum trabalho para si - uma identidade vocacional firme, mesmo que a identidade pessoal estivesse estilhaçada - e um sentido claro de propósito em meio a todo caos da doença. (BRYER; BARKS, 2005, p. 122).

Em uma carta de 1931, evidencia-se não só o mesmo eixo temático principal no que concerne aos escritos da autora, mas a coerência em seu estilo, como pode-se observar comparando algumas descrições. Ao descrever Scott, ele aparece ligado a "grutas", "gosmento" e "lugar": 
eu poderia tocar em sua nuca, onde o cabelo é curto e musguento, ou a testa, onde ele faz grutas pequenas no alto, mas fosse onde fosse, seria o lugar mais doce, o lugar mais doce (BRYER; BARKS, 2005, p. 147).

Scott, na verdade, aparece recorrentemente nas cartas descrito como se fosse um lugar, como em outra carta de 1931: "Aquele lugarzinho musguento em sua nuca é o lugar mais delicioso do mundo [...]” (BRYER; BARKS, 2005, p. 192), entre outras. $\mathrm{O}$ recurso é mobilizado também no romance ao descrever David Knight. Alabama "caminha" por ele como se ele fosse um lugar:

Arrastou-se para dentro da caverna amiga de sua orelha. A área lá dentro era cinzenta e fantasmagoricamente típica enquanto ela fitava ao redor dos profundos sulcos de cerebelo. Não havia um crescimento, nem uma substância em forma de flor para quebrar aquelas lisas circunvoluções, apenas a elevação túmida de matéria cinzenta e macia. [...] Ela seguiu adiante tropeçando e afinal chegou a medula espinhal. Vastas reentrâncias tortuosas a conduziram em círculos. Histérica, começou a correr. Perturbado por uma sensação de comichão no começo da espinha, David afastou os lábios dos dela. (FITZGERALD, 2014, p. 56) ${ }^{14}$

Considerando os biografemas para a análise, segundo Barthes, eles seriam:

se eu fosse escritor, já morto, como gostaria que a minha vida se reduzisse, pelos cuidados de um biógrafo amigo e desenvolto, a alguns pormenores, a alguns gostos, a algumas inflexões, digamos: "biografemas", cuja distinção e mobilidade poderiam viajar fora de qualquer destino e vir tocar, à maneira dos átomos epicurianos, algum corpo futuro, prometido à mesma dispersão [...]. (BARTHES, 2005, p. 17).

Pode-se notar como a criação ficcional de Zelda é permeada de eventos que marcaram a vida da autora como matéria bruta de seu romance e também como gênese da perspectiva da artista, principalmente enquanto mulher, o que reitera a ideia de que o romance não existe só como ficção, é marcadamente um romance autobiográfico.

Dentre as fontes sobre Zelda e Scott Fitzgerald, as cartas trocadas possuem frequentemente metáforas, eventos e imagens que estão também no romance. Em Save Me the Waltz, David é caracterizado como uma pessoa ligada à lua. Zelda, em carta de 6 de novembro de 1931, colocou Scottie, a filha do casal, em comparação a ele por meio dessa mesma característica: "Scottie às vezes se parece com você - Quer dizer, ela tem uma camada de luar em vez de pele e, olhando para ela, penso em você" (BRYER; BARKS, 2005, p. 161).

A partir das imagens recorrentes no romance que se ligam aos contos de fadas, pensando-se tanto em Alabama quanto em Zelda ligadas à imagem da "princesa", Zelda escreveu em carta para Scott quando namoravam:

Coração adorado, nosso conto de fadas está quase no fim e nós vamos nos casar e viver felizes para sempre, do mesmo jeito que a princesa presa 
na torre, com quem você tanto se preocupava - e que tanto me irritava pela constância da presença - me perdoe por todas as vezes que fui má e ressentida - por todos os minutos de infelicidade que lhe causei, quando podíamos ter sido felizes. (BRYER; BARKS, 2005, p. 80).

Alabama, por sua vez, também fora vista como a princesa na torre: "[...] e oh, minha querida, você é a minha princesa e gostaria de mantê-la fechada para sempre numa torre de marfim para meu deleite particular." (FITZGERALD, 2014, p. 58). ${ }^{15}$ Após essa passagem, Alabama pede que David não fale mais sobre a torre. "Knight", que, em inglês significa "cavalheiro", é a figura que "resgata" Alabama da vida no Sul, onde ela estava sob a tutela de seu rigoroso pai. "No destino da princesa está implícito o 'destino de mulher." (RAMALHO, 2001, p. 46), e esse destino de mulher implica a vida dedicada ao que é "do lar", ao que está na esfera privada, ligado à família e ao doméstico. Em uma amorosa carta escrita entre a primavera e o verão de 1931, na Clínica Prangins, Zelda retomou a princesa na torre:

Espero que saiba que há beijos esparramados em sua sacada, esta noite, de uma senhora que já foi, em três cartas distintas, uma princesa numa torre branca muito alta e que jamais esqueceu de sua posição elevada na vida e que espera de novo pelo seu amado real (BRYER; BARKS, 2005, p. 150).

Os lugares onde David Knight e Alabama Beggs moraram também são compatíveis com os lugares onde Zelda e Scott residiram, e correspondentes à cronologia que sucedeu a vida do casal, como o namoro no Sul durante a Primeira Guerra e o casamento durante o período entreguerras. Zelda treinou balé à exaustão, vendo em sua frente o casamento colapsar; o mesmo aconteceu com Alabama.

Harry T. Moore, no prefácio da obra abordada brevemente no início deste artigo, afirma que "este livro não deixa de ser uma autobiografia quase literal." (MOORE, 2014, p. 297). Pois, ainda que não ocorra o pacto autobiográfico necessário à autobiografia, existem brechas ficcionais que se abrem consideravelmente e que permitem considerar a obra como um romance autobiográfico.

A ficção se afirma no romance quando os nomes das personagens são anunciados, quando a protagonista se casa com o pintor (e não escritor) David Knight, quando aceita o convite para dançar em Nápoles, quando a cola na sapatilha de ponta a faz passar por uma cirurgia que a impede de continuar se dedicando à dança. Tais experiências de vida, pois, são diferentes daquelas vividas por Zelda. Zelda era a caçula de seis irmãos, não foi bailarina em Nápoles, e nem foi internada para passar por uma incisão em seus tendões. Todavia, o que marcou uma interrupção em suas expectativas sobre a vida foram as internações constantes em clínicas psiquiátricas até seus últimos dias.

"Eu sou um livro. Pura ficção." (FITZGERALD, 2014, p. 99) ${ }^{16}$ disse Alabama, afirmando seu próprio caráter ficcional como personagem, em um diálogo. A personagem não apenas carrega em si o nome da origem de sua criadora, pormenores (os bailes no clube), gostos (o balé) e inflexões (ambas do sul dos Estados Unidos), mas também a perspectiva sócio histórica de mulheres bran- 
cas e de classe social privilegiada. Ambas também são casadas com importantes artistas da época em que viveram - David Knight como pintor, Francis Scott Fitzgerald como escritor estadunidense que se consagrou no cânone literário norte-americano.

Além de o nome de Alabama retomar a origem dela própria e de Zelda, estabelecendo semelhança entre ambas, o lugar também marca o ciclo da bailarina que, que após viver em diferentes cidades, volta ao lar. Pode-se também pensar nos outros nomes do romance: Anthony Sayre era o pai de Zelda, enquanto o pai de Alabama chama-se Austin Beggs, Minerva (Minnie) Sayre era a mãe da escritora, e Millie Beggs é a mãe de Alabama.

Lejeune, no segundo momento em que escreve sobre o pacto autobiográfico, flexibiliza a necessidade da identidade afirmada no nome próprio, abordando as possibilidades de nomes serem semelhantes. Evidencia-se por essas semelhanças um importante indício que corrobora com essa visão da obra como "escrita de si", ainda que não nos termos da autobiografia propriamente dita: Anthony e Austin possuem a mesma inicial, Millie e Minnie possuem apenas algumas letras diferentes, enquanto Alabama é o estado onde Zelda nasceu.

Zelda e Alabama buscaram um entendimento sobre si, como pode-se ver em cartas ou no romance. Quanto a isso, Fryer afirma que "Alabama Beggs Knight, a personagem "paralela" a Zelda Fitzgerald, em Save Me the Waltz, chega perto de estabelecer seu próprio senso de identidade [...]" (FRYER, 1985, p. 325, tradução nossa). ${ }^{17}$ Alabama sente-se bem no lugar onde reconquista seu nome próprio, ao invés de ser reconhecida como parte da identidade de seu marido, "os David Knight" (ou "the David Knight" em inglês). Por sua vez, Zelda lidou com questões relacionadas a sua autoria, além de ser tratada como "the Fitzgerald" ou "a esposa de Scott Fitzgerald", apresentação questionável visto que a partir de um período, Zelda passou a ser conhecida por si só. A Metropolitan Magazine, em 1921, apresentou uma matéria cuja intenção era elogiar Zelda, no entanto a apresentou da seguinte forma:

A esposa de F. Scott Fitzgerald, que a colocou em seus dois brilhantes romances "This Side of Paradise" e "The Beautiful and the Damned" não precisa se juntar a Lucy Stone League para se identificar como uma personalidade. Tudo que Zelda diz e faz se destaca. (BRUCCOLI; SMITH, 2003, p. 78 , tradução nossa)..$^{18}$

Save Me the Waltz é uma obra cujo teor autobiográfico é constatado em prefácios e em textos acadêmicos que colocam Zelda ao lado de Alabama. Há semelhanças indubitáveis entre a ficção e a realidade que são encontradas em variados registros. Todavia, ler Save Me the Waltz como pura autobiografia seria um equívoco, pois Zelda não fez o pacto autobiográfico para configurar a obra como tal, e as semelhanças não são suficientes para afirmar isso. Sendo assim, não seria possível partir da obra propriamente dita para se falar de forma literal sobre Zelda ou Scott Fitzgerald, por exemplo, como é possível fazer servindose de textos que se firmam em dados verificáveis. A exemplo disso, citamos a 
biografia de Zelda escrita por Nancy Milford (1970), que conta com pesquisas e levantamentos sobre a escritora.

O entrecruzamento entre a vida e a ficção encontra-se no romance autobiográfico, uma vez que aqueles que conhecem a vida da autora são capazes de considerar as duas esferas, flexibilizando o olhar diante do que não se pode verificar extra textualmente e diante dos filtros estéticos próprios da literatura. Para os que não conhecem, Save Me the Waltz permanece um icônico romance sobre balé, sobre a mulher-artista, sobre buscar a própria vocação e o próprio lugar no mundo, e também sobre lidar com as dolorosas "incisões" que, por vezes, se operam na narrativa da vida.

\section{Considerações finais}

A busca da mulher por sua "voz" artística se estabelece como um dos principais motivos para que se leia Save Me the Waltz como um romance autobiográfico que coloca como protagonista uma personagem semelhante à autora em dados biográficos e pormenores (os biografemas). O romance é ficcional necessariamente porque não existe o pacto autobiográfico de forma explícita ou implícita, nem mesmo correspondentes nos nomes e no desfecho (Nápoles e a incisão para Alabama; a internação na clínica psiquiátrica para Zelda) - ao menos não de forma literal. A autora não fazer o pacto a isenta do compromisso do pacto, que seria "se comprometer a dizer a verdade sobre si mesmo" (LEJEUNE, 2014, p. 85). Dentre semelhanças e diferenças, é notável que tanto a escritora quanto a personagem partem da mesma perspectiva, como pode-se ver com TavernierCourbin a respeito dos desafios enfrentados pela artista:

Talvez isso espelhe as próprias dúvidas sobre si de Zelda Fitzgerald bem como sua crença de que apenas uma mulher extraordinariamente forte poderia superar as pesadas possibilidades das mulheres, casamento, pressão social, educação e maternidade na busca pela arte. (TAVERNIERCOURBIN, 1979, p. 42, tradução nossa). ${ }^{19}$

Revisitar a obra de Zelda é lançar luz sobre uma escritora esquecida pela tradição patriarcal, embora lembrada por outras questões não pertinentes a sua arte. Colocá-la sob os holofotes, não da curiosidade literária acerca de seu marido, mas sim como autora de obras é, conforme afirmam Macedo e Amaral, "um importante desafio de reescrita cultural para o feminismo" (2005, p. 195). Save Me The Waltz como romance autobiográfico traz a natureza cíclica da mulher que se vê frente a uma impossibilidade de força maior: a opressão de gênero. Embora a escritora mobilize recursos reconhecidos pelo próprio Lejeune como possíveis para autores de autobiografias, o pacto não se faz implicitamente nem explicitamente. O que temos, portanto, é uma obra que se entrecruza pelo romance e pelo fundo autobiográfico, fazendo-se romance autobiográfico. Esse entrecruzamento se articula sobretudo na perspectiva compartilhada entre a autora e a personagem, e está permeada de imagens e metáforas: pelo cíclico, 
pela valsa, pela "incisão" na vida, pela sensibilidade notável da mulher notável que foi Zelda Sayre Fitzgerald.

\section{Agradecimentos}

Agradecemos à Dra. Cátia Inês Negrão Berlini de Andrade, que muito contribuiu para as reflexões sobre as "escritas de si" contempladas neste artigo.

\section{Notas}

1. Este artigo é uma adaptação da dissertação de mestrado intitulada Emancipação e silenciamento em Save Me the Waltz (1932), de Zelda Fitzgerald, orientada por Cleide Antonia Rapucci.

2. No original: "There is no way to compare the pain of having to choose against the the pain of having no choice".

3. No original: "The wide and lawless generosity of their mother was nourished from many years of living faced with the irrefutable logic of the Judge's fine mind. An existence where feminine tolerance plays no role being insupportable to her motherly temperament, Millie Beggs, by the time she was forty-five, had become an emotional anarchist." (FITZGERALD, 2013, p. 41).

4. No original: "She knew, though, that she looked more frequently than her satisfaction in her appearance justified in the hope of finding something more than she expected." (FITZGERALD, 2013, p. 58).

5. No original: "Hearing little bits of things about the family characteristics that she too must have in her, was like finding she had all five toes when up to the present she had been able to count only four. It was nice to have indications about yourself to go on." (FITZGERALD, 2013, p. 50).

6. No original: "David, David, Knight, Knight, Knight, and Miss Alabama Nobody." (FITZGERALD, 2013, p. 68).

7. No original: "He verified himself in the mirror-pale hair like eighteenth-century moonlight and eyes like grottoes, the blue grotto, the green grotto, stalactites and malachites hanging about the dark pupil-as if he had taken an inventory of himself before leaving and was pleased to find himself complete." (FITZGERALD, 2013, p. 69).

8. No original: "I don't care," she repeated convincingly to herself: as neat an incision into the tissue of life as the most dexterous surgeon could hope to produce over a poisoned appendix. Filing away her impressions like a person making a will, she bequeathed each passing sensation to that momentary accumulation of her self, the present, that filled and emptied with the overflow." (FITZGERALD, 2013, p. 154).

9. No original: "It seemed to Alabama that, reaching her goal, she would drive the devils that had driven her-that, in proving herself, she would achieve that peace which she imagined went only in surety of one's self-that she would be able, through the medium of the dance, to command her emotions, to summon love or pity or happiness at will, having provided a channel through which they might flow." (FITZGERALD, 2013, p. 161).

10. No original: "[...] the South phrased itself in engraved invitation - to a party without an address. "Millie, you oughtn't to let her get so sunburned if she's going to wear that kind of clothes." (FITZGERALD, 2013, p. 58-59).

11. No original: "[...] whereas you are a moon person" (FITZGERALD, 2013, p. 119). 
12. No original: "It's a man's world," Alabama sighed, measuring herself on a sunbeam. "This air has the most lascivious feel." (FITZGERALD, 2013, p. 115).

13. No original: "In 1929-1930 Zelda wrote 5 sketches for College Humor. The magazine insisted that Scott's name be included in the by-line. A sixth story, "A Millionaire's Girl", appeared in The Saturday Evening Post credited only to F. Scott Fitzgerald due to a mistake in the Ober Office."

14. No original: "She crawled into the friendly cave of his ear. The area inside was gray and ghostly classic as she stared about the deep trenches of the cerebellum. There was not a growth nor a flowery substance to break those smooth convolutions, just the puffy rise of sleek gray matter. [...] She stumbled on and finally reached the medulla oblongata. Vast tortuous indentations led her round and round. Hysterically, she began to run. David, distracted by a tickling sensation at the head of his spine, lifted his lips from hers." (FITZGERALD, 2013, p. 71).

15. No original: " $[\ldots]$ and oh, my dear, you are my princess and I'd like to keep you shut forever in an ivory tower for my private delectation." (FITZGERALD, 2013, p. 71).

16. No original: "I am a book. Pure fiction." (FITZGERALD, 2013, p. 104).

17. No original: "Zelda Fitzgerald's parallel character, Alabama Beggs Knight in Save Me the Waltz, nearly succeeds in establishing her own sense of identity, independent of any man's opinion $[\ldots]$ ".

18. No original: "The wife of F. Scott Fitzgerald, who put her in two brilliant novels, "This Side of Paradise" and "The Beautiful and the Damned," does not need to join the Lucy Stone League in order to identify herself as a personality".

19. No original: "Perhaps this mirrors Zelda's self-doubts as well as her belief that only an extraordinarily strong woman could overcome the overwhelming odds of womanhood, marriage, social pressure, education, and motherhood in the pursuit of art".

\section{Referências}

ABREU, Caio Fernando. Prefácio à edição brasileira de 1986. In: FITZGERALD, Zelda. Esta Valsa é Minha. Tradução de Rosaura Eichenberg. 1. ed. São Paulo: Companhia das Letras, 2014. p. 291-293.

BARTHES, Roland. A morte do autor. In: O rumor da língua. São Paulo: Editora WMF Martins Fontes, 2012. p. 57-64.

BARTHES, Roland. Prefácio. In: Sade, Fourier, Loyola. São Paulo, Martins Fontes: 2005. p. 9-19.

BARTHES, Roland. Roland Barthes por Roland Barthes. Tradução de L. PerroneMoisés. SP: Cultrix, 1975.

BELLIN, Greicy Pinto. A crítica literária feminista e os estudos de gênero: um passeio pelo território selvagem. Revista FronteiraZ, São Paulo, n. 7, p. 1-11, dezembro de 2011.

BRUCCOLI, Matthew J.; SMITH, Scottie Fitzgerald; KERR, Joan P. (Edit.). The romantic egoists: a pictorial autobiography from the scrapbooks and albums of $\mathrm{F}$. Scott Fitzgerald and Zelda Fitzgerald. New York: Scribner, 2003.

BRYER, Jackson \& R. BARKS, Cathy W. (org.). Querido Scott, querida Zelda: as cartas de amor de Scott e Zelda Fitzgerald. Tradução de Beth Vieira. São Paulo: Companhia das Letras, 2005. 
CHEVAlier, J; GHEerbRANT, A. Dicionário de Símbolos: Mitos, Sonhos, Costumes, Gestos, Formas, Figuras, Cores, Números. Tradução de Vera da Costa e Silva et al. Rio de Janeiro: José Olympio, 2009.

FIGUEIREDO, Eurídice. Mulheres ao espelho: autobiografia, ficção, autoficção. Rio de Janeiro: EdUERJ, 2013.

FITZGERALD, Zelda. Esta valsa é minha. Tradução de Rosaura Eichenberg. $1^{\text {a }}$ edição. São Paulo: Companhia das Letras, 2014.

FITZGERALD, Zelda. (1932) Save Me the Waltz. In: BRUCCOLI, Matthew J. (Org). Zelda Fitzgerald: The collected writings. New York: Scribner, 2013. E-book.

FRYER, Sarah Beebe. Nicole Warren Diver and Alabama Beggs Knight: women on the threshold of freedom. Modern Fiction Studies. vol. 31, n. 2, p. 318-326, 1985. Disponível em: www.jstor.org/stable/26281498. Acesso em: 20 de março de 2021.

GENETTE, Gérard. O discurso da narrativa. Tradução de Fernando Cabral Martins. 3. ed. Lisboa: Veja, 1995.

LANIUS, Marcela; MARTINS, Marcia A. P. Uma vasta surpresa: os prefácios ao romance de Zelda Sayre Fitzgerald. Ilha do Desterro, Florianópolis, v. 72, n. 2, p. 205-224, agosto, 2019. Disponível em: http://www.scielo.br/scielo.php?script=sci arttext\&pid=S2175-80262019000200205\&lng=en\&nrm=iso. Acesso em: 20 de março de 2021.

LEGLEITNER, R.-A. The Cult of Artistry in Zelda Fitzgerald's Save me the Waltz. The F. Scott Fitzgerald Review. vol. 12, n. 1, p. 124-142, 2014.

LEJEUNE, Philippe. L'Autobiographie en France. Paris: Colin, 1971.

LEJEUNE, Philippe. O pacto autobiográfico: de Rousseau à Internet. Tradução de Jovita Maria Gerheim Noronha e Maria Inês Coimbra Guedes. Belo Horizonte: Ed. UFMG, 2014.

MACEDO, Ana Gabriela; AMARAL, Ana Luísa (Orgs.). Dicionário da Crítica Feminista. Porto: Edições Afrontamento, 2005.

MILFORD, Nancy. Zelda: A biography. New York: Haper \& Row, 1970.

MOI, Toril. Feminist, female, feminine. In: BELSEY, C. MOORE, J. (Ed.). The feminist reader: essays in gender and the politics of literary criticism. Houndmills: Macmillan, 1989. p. 117-129.

MOORE, Harry T. Prefácio à edição americana de 1968. In: FITZGERALD, Zelda. Esta Valsa é Minha. Tradução de Rosaura Eichenberg. $1^{\text {a }}$ edição. São Paulo: Companhia das Letras, 2014. p. 295-300.

NANNEY, Lisa. Zelda Fitzgerald's Save Me the Waltz as Southern Novel and Künstlerroman. In: The Female Tradition in Southern Literature. MANNING, Carol S. (Ed.). Urbana: University of Illinois Press, 1993. p. 220-234.

RAMALHO, Christina. Mulheres, Princesas e Fadas: A hora da Desconstrução. In: Revista Gênero. Niterói, v. 1, n. 2, p. 41-48, 2001.

SCOTT, Anne Firror. The Southern Lady: from the pedestal to politics, 1830-1930. Charlottesville and London: University Press of Virginia, 1995.

SHOWALTER, Elaine. A Literature of Their Own. In: EAGLETON, M. (Org.). Feminist Literary Reader: a reader. Cambridge, Mass. Blackwell, 1986. p. 11-15.

STREISSGUTH, Thomas. The Roaring Twenties. New York: Facts on File, 2007.

TAVERNIER-COURBIN, Jacqueline. Art as Woman's Response and Search: Zelda Fitzgerald's Save Me the Waltz. The Southern Literary Journal, vol. 11, n. 2, 1979, 
p. 22-42. Disponível em: www.jstor.org/stable/20077612. Acesso em: 20 de março de 2021.

WAGNER, Linda W. Save Me the Waltz: An Assessment in Craft. The Journal of Narrative Technique, vol. 12, n. 3, p. 201-209, 1982. Disponível em: www.jstor. org/stable/30225941. Acesso em: 20 de março de 2021.

WOOLF, Virginia. Um teto todo seu. 1. ed. São Paulo: Tordesilhas, 2014.

ZOLIN, Lúcia Osana. Crítica feminista. In: BONNICI, T.; ZOLIN, L. O. (org.) Teoria literária: abordagens históricas e tendências contemporâneas. 2. ed. Maringá: Eduem, 2005. p. 181-203.

Recebido em: 01/12/2020

Aceito em: 26/02/2021 